\title{
The Client-Consulting Relationship: A Case Study Of Critical Success Factors At MQ Telecommuniques
}

Steven H. Appelbaum (E-mail: shappel@vax2.concordia.ca), Concordia University, Montreal, Quebec, Canada Anthony J. Steed (E-mail: Anthony.steed@ sympatico.ca), Bell Canada, Montreal, Quebec, Canada

\begin{abstract}
The primary intent of this study then, is to examine recent projects involving external management consultants at MQ TeleCommuniques, from the employees' point of view, to measure the extent to which the aforementioned "critical success factors" were perceived as being evident. A secondary purpose was to examine which, if any, of these factors differ between more or less successful consulting projects with a view to building a model to predict employees' perceptions of the level of the projects' success. A third objective was to gather employee opinions on other factors that might contribute to the success of consulting projects. A fourth, and final, objective was to gather general employee opinions on the use of management consultancy at MQ TeleCommuniques. A total of 102 employees responded to a questionnaire consisting of 59 questions. A model including six independent variables was able to predict overall rating of project success, with an adjusted $R^{2}$ $=0.68, F=27.81$ ( $p<.0001)$. The significant variables, in order of importance, were:
\end{abstract}

1. the solution took into account our internal state of readiness;

2. $\quad$ the project included prototyping new solutions;

3. $\quad$ the project deliverables were clear;

4. $\quad$ the consultant partnered with the project team throughout;

5. the consultant was professional; and

6. $\quad$ the consultant understood our sense of urgency.

There were substantial differences seen on most measures between projects judged "successful" and projects judged "not successful". Nevertheless, it is encouraging that many of the success factors suggested in the literature, and proposed under "an ideal client-consultant engagement", were judged as present in management consulting projects at MQ TeleCommuniques, to one degree or another. General opinions of management consultants were mixed and somewhat negative. Employees at MQ TeleCommuniques certainly do not agree with the traditional benefits of management consultants promoted by the industry. Finally, the results of this study certainly support the anecdotal and theoretical models in particular those emphasizing the importance of process issues, the client-consulting relationship and their impact on project outcome.

\section{Introduction}

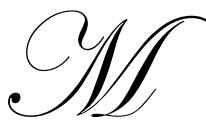

anagement consulting is here to stay. Though the industry may have been tarnished with last year's Enron scandal, it is nevertheless a resilient and highly successful trade. According to Industry Canada, the total number of management consulting establishments exceeded 26,000 in 1998, with total revenues approaching $\$ 5.7$ billion Cad. (Industry Canada, 2001). Since 1990, overall revenues in management consulting have grown $10-30 \%$ per year. Thus, the use of management consultants is very widespread. In fact, a US Department of commerce survey conducted in 1998, cited in Industry Canada's report, reported that $70 \%$ of all businesses and government organizations in Canada have used the services of a management consultant at least once in the last five years. Finally, they note that the management consulting industry is a key recruiter of business school 
graduates and has become a desirable employer, currently almost $40 \%$ of graduates in each MBA class attempt to enter the consulting industry.

Many authors have noted that, despite the size and significance of this industry, there is does not seem to be a correspondingly large wealth of empirical data on the practice of management consulting. Much of the theoretical framework described is derived from anecdotal evidence presented by numerous authors. Where available, this paper will draw upon empirical evidence. Moving from the general, to the specific, the paper will focus on aspects of the client-consulting relationship. A simple model of key critical success factors will be proposed. Finally, the paper will consider these critical success factors through a case study of MQ TeleCommuniques (MQTC).

\section{Success Factors Of The Consultant Engagement Process}

Armenakis and Burdg (1988) published an extensive review of consultation research up to the late 1980s. One key area proposed for further research is that of consultation success. Many investigations have cited criterion problems in determining the success of consulting efforts. They note that "hard" criteria, such as productivity and profitability are often not applicable to consultant programs. Instead, much of the research on consultation is based on criteria that such as self-reported measures of satisfaction, leadership and group process. Further, early studies of OD effectiveness tended to focus on comparisons between techniques used, rather than the actual behaviors exhibited by consultants during the intervention process.

O'Driscoll and Eubanks (1993) applied a behavioral competency model to organizational development interventions to assess perceived frequencies of a range of consultant behaviors, goal setting activities and their contribution to overall consultation effectiveness. The indicators of effectiveness they used included organizational outcomes, organizational processes and characteristics of the consultation itself. Major contributors to effective consulting, for consultants, were data utilization and setting of specific goals. Consultants who gathered information about the organization to increase their understanding of the group they were working with and to develop their intervention, who interpreted data for the client, and who provided feedback to the organization rated their OD program more highly; as did those who believed their intervention goals had been specific. These were also significant factors from the clients' point of view. Additional factors for clients, relating to successful outcomes, included having goals that were measurable and set by management, along with the consultant displaying competency in interpersonal skills and group process management.

O'Driscoll and Eubanks highlight the importance of gathering and interpreting information about the organization when designing and implementing OD interventions to both consultants and clients. Ford suggests that insufficient clarity is at the heart of most poor client-consulting relationships (Ford, 1985). Failure to identify the real problem, promising too much too soon, failure to specify roles and recommending unfeasible actions will all jeopardize the engagement. In addition, he argues effective communication is key.

How the consultant puts together the consulting process will affect the relationship with the client and possible future employment (McLarty and Robinson, 1998). McLarty and Robinson amended a model of consultancy developed earlier by Reddy-Phillips and McEvoy consulting of the University of Cincinnati. They describe task processes found in most consulting relationships, such as contract role, clarification, data generation, prioritization, actions and follow-up, as well as more subtle process issues related to interpersonal approaches and responses. "The ultimate goal of a successful closure must be seen as part of a process influenced by "process issues" which are simultaneously objective and subjective in nature. Good consulting practice requires a template for logical action." Both parties then, the client and the consultant, can influence and contribute to the success of the consulting project by focusing on such process issues.

McLachlin has several propositions, based on the literature, on aspects that are necessary, but not sufficient, for a successful consulting engagement (McLachlin, 1999). Consultants must exhibit integrity, in particular by always putting the client's best interest first. Clients must be involved in the project, and ready to change. It is key that there be a clear agreement, which may or may not be a formal contract, concerning project requirements and expectations. The client must ultimately control the engagement, partly by using clear and limited assignments. The con- 
sultants must be competent. Finally, there must be a good fit between clients and consultants along a number of dimensions, including models of consultancy, client expectations, consultant capabilities, and consultant type.

Schaffer argues, based upon a lengthy career in consulting, that the majority of clients that hire consultants, and most of the consultants that they hire, operate under a model of consulting that does not allow them to achieve full collaboration. Instead "it is typically expected that the consultants are accountable for creating the best possible solutions and tools, while the clients are accountable for using those solutions and tools to produce the improved results" (Schaffer, 2002).

Schaffer further describes a model of three specific outcomes necessary for a consulting project to be considered a success. First, the consultant must provide a solution or a method new to the client. Second, the client must achieve measurable improvement in its results by adopting the client's solution. Third, the client must be able to sustain the improvement over time. Consultants must be effective change agents and, further, they must join in accountability for the end result of their projects.

Schaffer describes the existence of an "implementation gap", that is the difference between all that the client would have to do to benefit from the consultant's recommendations and what the client is able of doing. He suggests that five factors or "fatal flaws" of conventional consulting increase the risk that an implementation gap will undermine the consulting project.

1. Consulting projects are defined in terms of the work the consultant will do and the "product" the consultant will deliver, but not in terms of specific client results to be achieved (Project is about change, not effecting change);

2. Project scope is determined mainly by subject to be studied or the problem to be solved, with little regard for the client's readiness for change (Ability, Motivation, Sense of Urgency);

3. Projects aim for one big solution rather than incremental successes;

4. Projects entail a sharp division of responsibility between client and consultant; there is little sense of partnership between them; and finally

5. Projects make labor-intensive use of consultants, instead of leveraged use.

Offering an alternate "high-impact" paradigm, which aligns well with much of the literature described so far, Schaffer suggests that key critical success factors are beginning with results, designing projects to match client motivation and dividing large projects into rapid cycle subprojects. Beginning with the results reinforces the notion of customizing the approach, aligning the client and consultant by focusing on a few critical results with clear, measurable short-term goals. Design projects to match client motivation and capability emphasizes that the project must carry a real sense of urgency at all levels, i.e. it must be done. It also links to ownership of the project, i.e. if people see that success depends on them, they will assume the responsibility. Dividing large projects into rapid-cycle subprojects implies proving in success quickly, through manageable phases and prototyping. It also enables the project team to rapidly absorb, use and benefit from solutions and build support by demonstrating quick wins. Schaffer's model (2002) also stresses process issues presented earlier, including extensive project communication and visible support of senior executives to set clear expectations for internal employees. Based on what has been presented so far in this paper, the next section proposes a model of key success factors for an ideal client-consultant engagement.

\section{Success Factors For An Ideal Client-Consultant Engagement}

It is generally accepted that how the consultant puts together the consulting process will affect the relationship with the client and consequently the success of the project. Based on the anecdotal views, conceptual frameworks and empirical studies described above, it is suggested that consulting engagements which possess the following success factors will lead to more favorable project outcomes: 


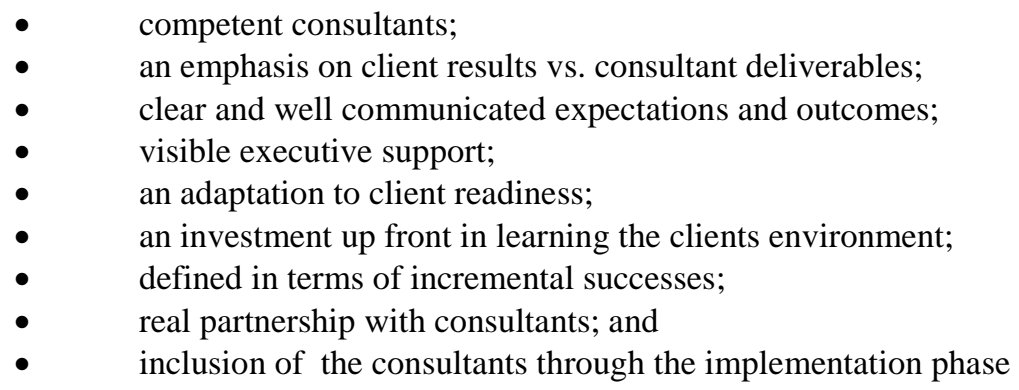

\section{Problem Statement}

MQ TeleCommuniques (MQTC) is no different from most major corporations in North America. External management consultants play an increasing role in formulation of business decisions. In fact, MQTC's holding company, spent hundreds of millions of dollars on consultant projects in 2002. Anecdotal evidence suggests that not every consultant engagement at MQTC is the same. Similarly, projects involving external management consultants achieve varying levels of success.

The primary intent of this study then, is to examine recent projects involving external management consultants at MQTC, from the employees' point of view, to measure the extent to which the aforementioned "critical success factors" were perceived as being evident. A secondary purpose is to examine which, if any, of these factors differ between more or less successful consulting projects with a view to building a model to predict employees' perceptions of the level of the projects' success. A third objective is to gather employee opinions on other factors that might contribute to the success of consulting projects. A fourth, and final, objective is to gather general employee opinions on the use of management consultancy at MQTC.

\section{Methodology}

Data for this study was collected via a confidential survey of MQTC employees. Due to the perceived sensitivity of this topic area, and to encourage a high level of participation, the survey was completed anonymously. A random sample of 250 middle and lower level managers was selected from the current company directory. The managers were selected from several departments judged to employ external management consultants, including Human Resources, Enterprise Services, Corporate Communications, Marketing Research and Marketing. The instrument was developed specifically for this study, drawing upon available literature and conceptual models.

\section{Respondents}

A total of 102 employees responded to the questionnaire. Four study invitations were undeliverable for technical reasons, so the final response rate was $41 \%$. This was well above the target response rate of $30 \%$. Very basic demographic information, such as employee level, tenure and department were collected to gauge how representative the respondents were of the sampled population. The demographic profile of respondents was comparable to the population sampled. Seventy-seven respondents (75\%) completed the survey in English, twenty-five (25\%) in French. Directors (Tier B) accounted for $21 \%$ of respondents, $54 \%$ were Team Leads (Tier C) and the remaining $26 \%$ were first level managers (Tier D).

\section{Measures}

The questionnaire consisted of a total of 59 questions. Respondents were asked whether, or not, they had detailed knowledge of a project involving an external management consultant in the past two years. If so, they were asked to think of the project they were most familiar with and keep it in mind while completing the first section of the survey. A series of statements were presented and respondents were asked to indicate they degree to which they agreed that the statements applied to the consulting project. Items focused on the initial stages of the project, the consultant, the objectives, deliverables, and the overall project including multiple outcome measures. The second 
section of the questionnaire included a series of questions related to perceptions of the use of management consultants in general at MQTC. Statements included in the questionnaire were designed to elicit responses on the success factors described in the "ideal" client-consultant engagement described previously.

\section{Results}

An impressive $84 \%$ of respondents indicated that they were personally familiar with specific projects at MQTC involving external management consultants in the past two years. Almost $80 \%$ of these individuals were either part of the project team (45\%) or interacted with the consultant during the project (34\%). An additional $11 \%$ did not fall into the first two categories, but were affected by the project outcome. Only $8 \%$ of the respondents were only indirectly familiar with the consulting project.

Only six respondents, in total, were actually involved in the hiring decision. This is somewhat less than might have been initially expected, suggesting that the hiring decisions may well be taken above Director's level. The first set of questions related to specific consulting projects, respondents were asked to indicate the extent to which they agreed with a series of statements about that project. The response was measured on a 10-point scale, from 1-Totally Disagree to 10-Totally Agree. For this analysis, \% agreement was calculated using ratings of seven and above. Marketing Research at MQTC adopts this standard, as a response of less than 7 cannot be taken as evidence of overwhelming agreement to any statement. In addition, the mean score for each item was calculated. Table 1 shows items related to respondents evaluation of the consultant.

Table 1 - The Consultant

\begin{tabular}{|c|c|c|c|}
\hline Question & $\mathbf{n}$ & $\begin{array}{c}\text { \% Agree } \\
(7-10)\end{array}$ & $\begin{array}{l}\text { Mean } \\
\text { Score }\end{array}$ \\
\hline The consultant was professional & 82 & $90 \%$ & 7.9 \\
\hline The consultant communicated well with the team & 82 & $61 \%$ & 6.7 \\
\hline The consultant shared in the project risk & 82 & $35 \%$ & 5.2 \\
\hline The consultant took time to learn MQ TeleCommuniques's environment & 82 & $44 \%$ & 5.9 \\
\hline The consultant understood our internal abilities & 82 & $38 \%$ & 5.3 \\
\hline The consultant understood our motivation & 81 & $65 \%$ & 6.9 \\
\hline The consultant understood our sense of urgency & 81 & $73 \%$ & 7.3 \\
\hline The consultant emphasized what changes were necessary to meet the objectives & 81 & $49 \%$ & 6.4 \\
\hline The consultant emphasized how to effect the changes at MQ TeleCommuniques & 81 & $32 \%$ & 5.6 \\
\hline The consultant defined the project in terms of specific client results & 79 & $43 \%$ & 6.1 \\
\hline The consultant defined the project in terms of their own specific deliverables & 78 & $60 \%$ & 6.4 \\
\hline
\end{tabular}

According to respondents, the consultants' relative strengths appeared to be their professionalism, their understanding of clients' sense of urgency and motivation, and their communication with the team. Respondents definitely agreed that the consults working on the projects were professional, with $90 \%$ positive and a mean rating of 7.9. In terms of understanding the client's sense of urgency, responses were $73 \%$ positive, with a mean score of 7.3. Similarly, the consultant understood our motivation was strong at $65 \%$ positive, and a mean score of 6.9 . They were also rated quite positively for their communication with the team, $61 \%$ agreeing with an average score of 6.7. That should not be entirely surprising, as MQTC typically works almost exclusively with the top tier consulting companies in the industry. Many have long standing relationships with MQTC.

It is important to note then, that there appears to be evidence of these key factors appearing rather consistently in the consulting projects that were rated.

Responses were more mixed, on several items related to the degree to which the consultant focused on the clients, such as the consultants' taking time to learn about MQTC's environment, with 44\% positive and a mean of 5.9; emphasizing the changes necessary to meet the project objectives, with $49 \%$ positive and a mean of 6.2 ; and defining the project in terms of client results with $436 \%$ positive and a mean of 6.1 . While these dimensions are evi- 
dent in the consulting projects, they are not judged to be present as consistently across the projects. That is, almost have of respondents did not agree that they were positively displayed.

Weaker items for the consultants were those loosely related to the motives of the consultants, and the fit of their work with MQTC. For example, there did not seem to be much perception of shared risk with only $35 \%$ of respondents agreeing that the consultant actually shared in the project risk and a mean of 5.2. Intuitively this sounds like an appealing approach to consulting, but it does not seem to be prevalent in the working relationships at MQTC.

Also, consultants' understanding of the organizations internal abilities was considered low, at $38 \%$ agreement and a mean of 5.3. In a large organization like MQTC, there is a wide range of capabilities. Consultants were judged less approvingly on emphasizing how to effect the changes at Bell, with 32\% positive and a mean of 5.6. Implementing change in an organization as big as MQTC can be daunting so intuitively this is a huge requirement. Finally, consultants were judged as tending to define the project in terms of their own specific deliverables, with $60 \%$ agreement and a mean of 6.4 .

This is contrary to a customized approach, or one that incorporates the unique needs of the project team. In the case of these weaker items then, the majority of respondents judged them as being absent from the projects they were rating.

\section{Regression Model}

The penultimate step in this phase of the analysis was to see if it was possible to construct a simple model to predict ratings of overall project success. To do this, a stepwise linear regression procedure was used to construct a model. In the first case, the dependent variable used was the rating of project success (from 1 to 10). The independent variables included the respondents' ratings of all aspects of the project, excluding the outcome measures (listed in Table 6). Stringent criteria of $\mathrm{p}<0.25$ for model entry, and $\mathrm{p}<0.05$ for model retention were used. The CP statistic was examined at each step to find an optimal number of variables for inclusion in the model.

Residual plots were analyzed, the sign pattern of the model coefficients evaluated, the significance of the parameter estimates was considered, VIF checked for co linearity, correlations between the independent variables considered and an analysis of influential observations conducted. Diagnostic analyses suggest the model is robust, the goodness of fit of the model is satisfactory, and the results can be generalized. The model results are shown in Table 2 .

A model including six independent variables was able to predict overall rating of project success, with an adjusted $\mathrm{R}^{2}=0.68, \mathrm{~F}=27.81$ ( $\left.\mathrm{p}<.0001\right)$. The significant variables, in order of importance, were:

1. the solution took into account our internal state of readiness;

2. the project included prototyping new solutions;

3. the project deliverables were clear;

4. the consultant partnered with the project team throughout;

5. the consultant was professional; and

6. the consultant understood our sense of urgency.

Thus there were, in fact, substantial differences seen on most measures between projects judged "successful" and projects judged "not successful". The last section of results examines employees" perceptions of management consultants in general. 
Table 2 - Model Predicting Rating Of Project Success.

Whole Model Actual By Predicted Plot

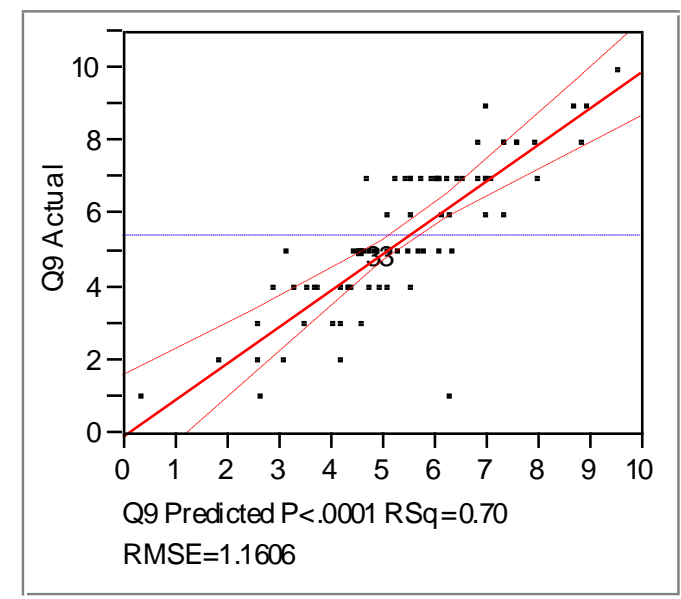

Summary Of Fit

\begin{tabular}{|ll|}
\hline RSquare & 0.704527 \\
RSquare Adj & 0.679201 \\
Root Mean Square Error & 1.160558 \\
Mean of Response & 5.454545 \\
Observations (or Sum Wgts) & 77 \\
\hline
\end{tabular}

Analysis Of Variance

\begin{tabular}{|lccc|}
\hline Source & DF & Sum of Squares & Mean Square \\
\hline Model & 6 & 224.80827 & 37.4680 \\
Error & 70 & 94.28264 & 1.3469 \\
C. Total & 76 & 319.09091 & \\
\hline
\end{tabular}

Parameter Estimates

\begin{tabular}{|lcccc|}
\hline Term & Estimate & Std Error & t Ratio & Prob>|t| \\
\hline Intercept & -2.32326 & 0.810491 & -2.87 & 0.0055 \\
The consultant was professional & 0.2439544 & 0.097989 & 2.49 & 0.0152 \\
Understood our sense of urgency & 0.1829827 & 0.076814 & 2.38 & 0.0199 \\
Project deliverables were clear & 0.2319746 & 0.085837 & 2.70 & 0.0086 \\
Project included prototyping & 0.157511 & 0.050056 & 3.15 & 0.0024 \\
Took into account our internal state of readiness & 0.2700331 & 0.077921 & 3.47 & 0.0009 \\
Partnered with the project team throughout & 0.1585443 & 0.063651 & 2.49 & 0.0151 \\
\hline
\end{tabular}




\section{Management Consultants In General}

The final section of the questionnaire addressed general opinions regarding management consultants in general. They were not meant to be tied to any project in particular. Again, respondents were asked to indicate the degree to which they agreed with each statement, on a 10-point scale. The results are shown in Table 3.

The first four-statements dealt with perceptions of the benefits of consultants, i.e. those purported by the industry itself such as objectivity, ideas, expertise and speed. Over half of respondents agreed with the supposition that management consultants provide objective advice, 52\% agreed with a mean score of 6.2. Slightly more agreed that they provide new ideas, with $57 \%$ positive and a mean score of 6.5 . Responses were less supportive of the latter two benefits, expertise and speed. Consistent with the open-ended comments identified during interviews, only 39\% of respondents feel that consultants have skills that are lacking internally (at MQTC) with a mean score of 5.3. Some $44 \%$ of respondents agreed that consultants provide solutions more quickly than internal resources, with a mean score of 5.9. From MQTC employees' point of view, there is only weak support for the benefits commonly promoted by the industry.

Interestingly, cost is another matter entirely. Only $7 \%$ of respondents believe that management consultants are less expensive than using in-house resources, with a mean score of 3.0. There were also several comments questioning the cost/benefit equation of using management consultants on the open-ended question on project successes. This is certainly a sore point at MQTC, having just undergone another wave of "streamlining" in the first quarter of 2003.

Respondents' impressions were generally negative toward the way management consultants work. That is, only 36\% agreed that management consultants customize their solutions to suit MQTC, with a mean score of 5.6. This supports comments on the in open-ended question, that management consultants often have a solution in mind, or use a cookie cutter approach. Also, one third agreed that management consultants have the ability to create action based upon their recommendations, with a mean score of 5.5. This is, no doubt, linked to the feedback that they are not often involved in implementing their plans, coupled with the notion that their recommendations are considered unrealistic at times.

In terms of management consultant's impact on MQTC, respondents did not perceived in them as improving MQTC's competitiveness, performance or capabilities. Only $28 \%$ agreed that management consultants help to make MQTC more competitive with a mean score of 5.3. Results were the same for management consultants improving MQTC's performance. As for capabilities, only 24\% agreed with a mean score of 5.2. They are not seen as changing MQTC's organizational culture, with 24\% agreed and a mean score of 4.6.

When asked, employees almost unanimously disagreed that management consultants should be used more often. Only $3 \%$ of those surveyed agreed with this statement, with a mean score of 3.8. There was also a sense that management consulting projects are not, in fact, well managed at MQTC with only $23 \%$ agreeing and a mean score of 4.7 .

Finally, respondents were given the opportunity indicate what issues they feel are important to the successful use of Management Consultants at MQTC in an open ended question. A total of 37 individuals, almost $40 \%$ of the sample, provided detailed comments.

The feedback was generally more balanced than originally anticipated. That being said, the most common feedback was that MQTC should use internal resources first. Several individuals suggested that management consultants should only be engaged at the request of internal resources. The second theme was related, but emphasized that consulting projects should work more closely with MQTC resources on projects, to leverage in-house knowledge and expertise. Several individuals stressed the importance of doing this to facilitate development of realistic solutions, and to facilitate knowledge transfer. The final theme centered on Governance. There is a sense that consulting projects are not managed consistently. Comments stressed greater accountability, in particular, for management consultants with systematic measurement of their projects and more clarity in roles and responsibilities. 
Table 3 - Management Consultants In General

\begin{tabular}{|c|c|c|c|}
\hline Question & n & $\begin{array}{c}\text { \% Agree } \\
(7-10)\end{array}$ & $\begin{array}{l}\text { Mean } \\
\text { Score }\end{array}$ \\
\hline Management consultants provide objective advice & 97 & $52 \%$ & 6.2 \\
\hline Management consultants provide new ideas & 97 & $57 \%$ & 6.5 \\
\hline Management consultants provide expertise which is lacking in-house & 97 & $39 \%$ & 5.3 \\
\hline Management consultants are able to provide solutions more quickly than our internal resources & 96 & $44 \%$ & 5.9 \\
\hline Management consultants are less expensive than using in-house resources & 97 & $7 \%$ & 3.0 \\
\hline Management consultants customize their solutions to suit MQTC situation & 97 & $36 \%$ & 5.6 \\
\hline Management consultants have the ability to create action based on their recommendations & 96 & $33 \%$ & 5.5 \\
\hline Management consultants help to make MQTC more competitive & 96 & $28 \%$ & 5.3 \\
\hline Management consultants improve MQTC's performance & 94 & $28 \%$ & 5.3 \\
\hline Management consultants improve MQTC's capabilities & 94 & $24 \%$ & 5.2 \\
\hline Management consultants change our organizational culture & 94 & $24 \%$ & 4.6 \\
\hline MQTC should use management consultants more often & 96 & $3 \%$ & 3.8 \\
\hline Management consulting projects are generally well managed at MQTC & 93 & $23 \%$ & 4.7 \\
\hline
\end{tabular}

\section{Discussion}

There are certainly some limitations to this study. For instance, the results reflect employee's subjective perceptions of project success and outcome. No attempt was made to try to include "harder" more objective measures of project success. The study also focused primarily on "Intermediate" clients. It is possible that other client groups may have considerably different opinions. In addition, it was not possible to sample based on projects, i.e. there was no way to know the magnitude or context of which projects respondents were rating. This may have introduced some bias among respondents.

Nevertheless, it is encouraging that many of the success factors suggested in the literature, and proposed under "an ideal client-consultant engagement", were judged as present in management consulting projects at MQTC, to one degree or another.

Employee perceptions were most positive towards the professionalism of consultants, their understanding of our sense of urgency and motivation, and the efficacy of their communication. There was also evidence that employees perceive that consultant projects have strong executive support. Despite these factors, there were still mixed ratings of the impact and success of consulting projects at MQTC.

Client focus, clarity of objectives, deliverables and outcomes, adaptation to client readiness, up front learning about our environment, prototyping and emphasis on incremental successes, partnership with the project team and availability of the consultants for the implementation phase were all key to improved project outcomes. They were all more evident in projects rated as "successful" than not, and they are able to predict subjective ratings of project success.

The findings certainly suggest opportunities for improvement. The results suggest that no consistent approach is being taken with external management consultants at MQTC, which is reinforced by open-ended feedback from mid and lower level managers. Recommendations for MQTC include establishing guidelines for consulting projects including:

- $\quad$ A greater push for clarity, internal communication and buy-in;

- Insisting that consultants invest more time in learning about MQTC, its environment, capabilities and inhouse strengths;

- $\quad$ Recognition that implementation planning and execution must be part of every consulting mandate; and

- Developing clearer Governance procedures and establishing more consistent processes surrounding external consulting engagements 
General opinions of management consultants were mixed and somewhat negative. Employees at MQTC certainly do not agree with the traditional benefits of management consultants promoted by the industry.

MQTC may also want to investigate one issue that came out of the open-ended responses. Although not part of the original study, there was sufficient feedback to warrant investigating sensitivities surrounding internal consultancy, and possibly exploring ways to use internal consultancy as a compliment to eternal management consultants.

Finally, the results of this study certainly support the anecdotal and theoretical models reviewed earlier, in particular those emphasizing the importance of process issues, the client-consulting relationship and their impact on project outcome.

\section{References}

1. Armenakis, A. A., Burdg, H. B. (1998), "Consultation Research: Contributions to Practice and Directions for Improvement”, Journal of Management, Vol. 14, No. 2, pp. 339-365.

2. Ford, C. H. (1985), "Developing a Successful Client-Consulting Relationship", in Bell, C. R. and Nadler, L.N. (Eds.), Clients \& Consultants: Meeting and Exceeding Expectations, Gulf Publishing Company, Houston, TX.

3. "Management Consulting Industry", Industry Canada, March 2001.

4. McLachlin, R. (1999) "Factors for consulting engagement success", Management Decision, Vol. 37. No. 5, pp. 394-402.

5. McLarty, R. and Robinson, T. (1998) "The practice of consultancy and a professional development strategy", Leadership \& Organizational Development Journal, Vol. 19, No. 5, pp. 256-263.

6. O'Driscoll, M. P. and Eubanks, J. L. (1993) "Behavioral Competencies, Goal Setting, and OD Practitioner Effectiveness", Group \& Organization Management, Vol. 18, No. 3, September, pp. 308-327.

7. Schaffer, R.H. (2002) High-Impact Consulting: How Clients and Consultants Can Work Together to Achieve Extraordinary Results, Jossey-Bass, San Francisco, CA. 